\title{
Effect of nursing interventions for stress management
}

\begin{abstract}
The aim of this research is to identify the effect of nursing interventions for stress management. Materials and methods: Pre-experimental research, pre-test/post-test. The study was formed of participants from the university community, and sampling was done according to availability of the person, since the participant involved had to be willing to receive the intervention and participate in all stages of the investigation. The sample size included a total of 33 participants. The following was used: a) biosociodemographic and health data collection questionnaire, b) a stress reactivity index (SRI) proposed by Gonzales de Rivera in 1990, and c) objective data which were cortisol levels, blood pressure, cardiac and respiration rate. The intervention included nursing counseling for stress management, which consisted of seven sessions to manage stress in a healthy way; the intervention included respiration techniques, guided meditation, relaxation exercises, massage therapy, music therapy and aromatherapy. The results showed that the SRI decreased from 1.68 to 0.8824 , also, a decrease was shown in the mean cortisol level after the nursing interventions from $12,78(\mathrm{SD}=5.29) \mu \mathrm{g} / \mathrm{dL}$ to $11,85(\mathrm{SD}=4.75) \mu \mathrm{g} / \mathrm{dL}$. In conclusion: It has been found that nursing interventions and counseling have a beneficial effect on SRI and cortisol, and are effective for managing stress.
\end{abstract}

Keywords: stress, nursing, students, occupational health, alternative therapies
Volume 2 Issue 2 - 2018

María Olga Quintana-Zavala, Claudia Figueroa-lbarra, Rosa Maria TinajeroGonzález, Rosa Elena Salazar-Ruibal, Julio Alfredo García-Puga, María del Carmen Valle-Figueroa, Eva Angelina Hernández-Villa, Carolina Angelica Soto-Coronado, María José Gurrola-Castillo

Department of Nursing, University of Sonora, Mexico

Correspondence: Quintana Zavala María Olga, Chief of Nursing Department of the University of Sonora, Blvd. Luis Encinas y Rosales S/N, Col. Centro, Hermosillo, Sonora, México, CP 83000 Tel 662259 2165/4703, Email

olga_quintana@enfermeria.uson.mx

Received: February 20, 2018 | Published: March 21, 2018
Abbreviations: SRI, stress reactivity index; SD, standard deviation; NIC, nursing intervention classification; BP, blood pressure

\section{Introduction}

In Mexico, cardiovascular diseases occupy first place in morbidity and mortality, which is worrisome due to the high number of deaths from heart ischemia. In 2013, there were 623 thousand 600 deaths in this nation. ${ }^{1}$ Stress and cardiovascular diseases are intimately related. Today the predisposing factors to suffer from cardiovascular diseases are known, which are the following, age, genetic load and sex. However, modifiable or controllable risk factors exist, such as diet, physical activity, smoking, excessive alcohol consumption and stress levels, in which various health actions can be carried out to reduce their impact. In relation to stress, it's known that in small episodes, it can be positive by activating mechanisms that permit an increase in focus towards situations that may endanger safety and or life, and therefore prepare to fight or flee from a dangerous situation. ${ }^{2}$ However, excess stress can have negative consequences on health and adversely affect the immune, cardiovascular, neuroendocrine and central nervous systems. ${ }^{3}$ In recent decades, it has been identified that stress, behavioral and emotional aspects, have approximately the same potency of association with coronary artery diseases as hypercholesterolemia, arterial hypertension and smoking, and are significant risk factors as important as the traditional risk factors. ${ }^{4}$

In the same way, individuals with greater cardiovascular reactivity to acute mental stress have greater increases in circulating levels of IL-6 and TNF after the stressor, which can then stimulate an inflammatory cascade that plays a crucial role in atherogenesis, the plaque formation below the intima in the arterial wall. ${ }^{5}$ Stress affects individuals of all professions and ages, regardless of sex, nationality, educational background or role. It is estimated that during one year, work-related stress affects at least one third of the workforce. ${ }^{6}$ The high personal and social costs generated by work related stress have led international organizations such as the European Union and the World Health Organization, to insist more and more on the importance of prevention and control of stress in the labor field. ${ }^{7}$ Studies have been carried out on stress in the academic and work areas, in search for methods to combat stress using alternative practices and those focused on knowing the relationship that exists with stress and cardiovascular diseases. In countries such as the United States, Colombia, and the United Kingdom studies show that implementing alternative practices such as relaxation therapies, laughter and breathing techniques, positively influence the reduction in levels of depression, anxiety, stress, perceived stress, diastolic blood pressure, triglycerides, high density lipoproteins. These studies conclude that the integration of alternative practices in the health system will allow to rescue important aspects of care..$^{8-11}$ In nursing the Nursing Intervention Classification $(\mathrm{NIC})^{12}$ exist, which includes a whole range of nursing interventions from general practice to specialty areas. The interventions include treatments and prevention of physiological and psychosocial aspects; treatments and disease prevention; promotion of health; interventions for individuals, families and communities and indirect care. They can be used in any practical context, regardless of philosophical orientation. The term "nursing intervention" refers to all treatment, based on the knowledge and clinical judgment performed by a nursing professional to favor the patient's expected outcome. ${ }^{12}$ Therefore, the present study has the objective of identifying the effect of nursing interventions for the management of stress in a group of academics, employees and university students. 


\section{Materials and methods}

\section{Type of study}

Pre-experimental: Pre-test / post-test design with only one group. ${ }^{13}$

Population, sampling and sample: The population corresponds to the university community. Sampling was done for convenience, because the person should be willing to receive the intervention and participate in all of the stages of the project, the sample consisted of a total of 33 participants.

Inclusion criteria: Form a part of the university community. Affiliated students, employees and academics who agree to participate in the intervention program.

Exclusion criteria: Not belong to the university community. Attend psychological therapy. Students, employees and academics of the University who do not accept to participate in the intervention program.

\section{Study variables}

Independent variable: Nursing Interventions. Seven individual standardized sessions, according to NIC. (Guided meditation, breathing techniques and progressive muscular relaxation, relaxation exercises, and therapeutic massage, all with aromatherapy and music therapy).

Dependent variables: Stress reactivity index (SRI), Cortisol level, Blood pressure, Pulse, Respiration rate.

Intervening variables: Sex, Age, Schooling, Marital status, children, Extra occupation, important diseases in the last year, significant losses in the last year.

\section{Instrument to obtain data}

A biosociodemographic and health data collection form was used, the stress reactivity index proposed by Gonzales de Rivera in 1990 in its 32-items which consists of an introduction on the concept of reactivity in the face of stress, and from a list of the 32 most common reaction patterns, the instrument was self-administered, and a form was used to collect objective data such as cortisol levels, blood pressure, pulse and respiration.

\section{Data collection procedure}

This research had a favorable dictum from the Ethics and Research Committee of the University of Sonora, once the favorable dictum was obtained, the university community was invited to participate by electronic means and posters placed in strategic points of the university, such as the student dining room, bulletin boards and main offices of the different departments; People who were interested in participating were asked to register at the Nursing Department's office, giving a one-week registration period, once the list of interested participants was ready, the experimental group was formed.

Participants were explained the objective of the study and were asked to read and sign an informed consent letter, once signed, an interview was conducted to collect biosociodemographic and health data, in addition to filling the instrument stress reactivity index (SRI) , and the evaluation of physiological variables, among which were laboratory sample analysis. For the laboratory examination, the participants were summoned to the clinical analysis laboratory of the University of Sonora, they required a minimum of an eight-hour fast, the tests were drawn from 7:30 am to 8:30 am. The conditions, risks and sensations of the procedure to be performed were explained to the participant. . They were asked to sit in a seated position with arm support to puncture on a firm surface that allowed slight flexion of the elbow. Prior to hand hygiene technique suggested by the World Health Organization from the person that was to perform the procedure. The tourniquet (elastic band of 20 to $30 \mathrm{~cm}$ in length) was placed at the level of the middle third of the arm for no longer than three minutes, by localized palpation, in either the median basilic vein, ulnar median or radial vein. Once the vein to be punctured was identified, antisepsis was performed (sanitization) with $70 \%$ isopropyl alcohol swab or sterile pads impregnated with alcohol in three circular times, starting with circular movements of the puncture site and up to approximately five centimeters outside the puncture site. Area to puncture; the alcohol was allowed to dry for 10-15 seconds. Once the time elapsed, the operator proceeded to perform the puncture at an angle of 45 degrees with a syringe of three or five milliliters with a 21-gauge needle for $32 \mathrm{~mm}$ plastipack until a blood sample was obtained, and between 3.5 and $5 \mathrm{ml}$ of blood was drawn and transferred to a vacuum tube plug BD VACUTAINER yellow $3.5 \mathrm{ml}(13 \times 75 \mathrm{~mm})$ or $5.0 \mathrm{ml}(13 \mathrm{X} 100$ $\mathrm{mm}$ ) with gel plug hemogard additive, silica and gel. The needle was previously removed and a swab was placed over the puncture site to create hemostasis under pressure for one minute or until blood stopped flowing. The sample was labeled with the identification data of the participant and processed in the clinical analysis laboratory of the University of Sonora. The results issued by the laboratory were collected by the researchers at the laboratory facilities and formed part of the database. The safety of the participant was guaranteed in case of suffering biomedical complications such as vertigo, fainting, bleeding or infection which were not necessary since there was no adverse events or complications. To measure the pulse of the subjects, the following equipment was used: clock with a second hand, record sheet, pencil or pen. The method consisted of:

i. Placing the subject with the arm resting on a fixed surface, with the hand extended and palm downwards.

ii. Place the tips of the index and middle fingers on the radial artery, making light pressure to perceive the pulse.

iii. Count the number of beats for a full minute.

The following equipment was used to measure respiration: clock with a second hand, record sheet, pen or pencil. The method was:

i. Keep the patient at full rest.

ii. Hold the wrist as if it were to take the pulse.

iii. Count the number of breaths at each elevation of the chest, d) write on the registration card the number of breaths per minute.

A Welch Allyn adult aneroid baumanometer and 3M Litmann stethoscope were used to measure the blood pressure of the subjects participating in the study. The method consisted of:

i. Explaining the procedure to the subject.

ii. Asking the participant to sit and support arm on a firm surface with the palm of the hand facing up. 
iii. Place the cuff of the baumanometer around the arm, three centimeters above the elbow.

iv. Locate the humeral pulse with the index and medium fingers.

v. Place the capsule of the stethoscope on the area corresponding to the humeral artery, where the pulse was identified.

vi. Close the valve of the insufflator pear and pump the bulb of the baumanometer approximately $20 \mathrm{~mm}$ above the value where the systolic pressure is expected.

vii. Loosen the screw of the bulb to let the air out slowly, observing the descent; read the point where the first heart sound corresponding to the systolic or maximum pressure is heard.

viii. Continue with the gradual exit of the air and read in the baumanometer when the last heart sound is stopped, which corresponds to the diastolic or minimum pressure; keep the figures in mind.

ix. Allow the air to leave the bracelet.

$\mathrm{x}$. Remove the stethoscope and the bracelet, and record the blood pressure on the collection card.

After the measurements were taken, the nursing intervention was carried out on an individual basis by appointment, once a week for seven weeks. The final evaluation was carried out, which consisted in the collection of biosociodemographic data and of physiologic factors, also the participants must fill out stress reactivity index instrument once again, as well as, sample of laboratory, for the second time.

\section{Nursing intervention for stress management and stages of the project}

The nursing intervention for stress management consisted of seven sessions to manage stress in a healthy way.

Session 1: Pre-test, consisted in taking a blood sample to obtain cortisol levels and stress reactivity index before starting with nursing intervention sessions.

Session 2: The second session consisted in taking vital signs before beginning with the intervention, later it was taught as well as practiced deep breathing techniques to relieve stress and /or tension along with participant. In addition, a guided progressive muscle relaxation technique was performed, where the participant was instructed to tense and relax each specific area of the body to achieve greater relaxation at the end of the exercise, all accompanied by aromatherapy using essential oils and musictherapy. At the end of the session, vital signs were taken.

Session 3: The third session consisted of taking vital signs before starting the intervention, then the participants where guided through a meditation, accompanied with aromatherapy using essential oils and musictherapy. At the end of the session, vital signs were taken.

Session 4: This session consisted in the taking of vital signs before the intervention, later relaxation and stretching exercises were instructed to activate and later relax the muscles and rest, all accompanied by musictherapy and aromatherapy with essential oils, at the end of the session vital signs were taken.

Session 5: The session consisted of taking vital signs before the intervention, then placing the participant in therapeutic bed to provide therapeutic massage with an anti-stress approach, accompanied by musictherapy and aromatherapy with essential oils. At the end of the intervention, vital signs were taken.

Session 6: Post-test, blood sampling were drawn in the clinical laboratory of the University of Sonora, to obtain cortisol levels and subsequent stress reactivity index of all nursing intervention sessions.

Session 7: The last session consisted in communicating with the participants for the delivery of results (cortisol and stress reactivity index) before and after the nursing sessions. In addition, doubts were clarified and they were thanked for their participation in the investigation.

\section{Statistical analysis plan}

Organization, processing and statistical analysis were carried out in the IBM SPSS version 21 for Windows program. To corroborate if the data come from a normal distribution, the nonparametric Kolmogorv-Smirnov test was used. The variables were analyzed with the Chi square test and Student's T test. The level of significance admitted was 0.05 .

\section{Ethical considerations}

The present study was based on the provisions of the Declaration of Helsinki of the World Medical Association, regarding the ethical principles for medical research in humans, as well as the Regulation of the General Law on

Health in Research. This investigation was considered minimal risk. Individuality was guaranteed in each intervention and the collection of laboratory samples through the extraction of blood was carried out by trained professional personnel. Attention was to be provided in case of any complication related to the procedure, however no complication arose. The participants were guided on the procedure by monitoring them in case any complication emerged, however minimal. The above was in charge of the responsible researcher and the project's collaborators. Each participant of the project had the right to terminate their collaboration at any time, if so decided, without retaliation to their person. It was guaranteed that the database did not include any data that could allow participants to be identified and security measures were taken to protect the related documents, guaranteeing that the data could not be seen or used by other people outside the study, nor for different purposes. There was an informed consent letter, which was signed in agreement by the participants and the responsible researcher. As a personal compensation, each participant acquired elements to apply the stress management techniques in their daily life, in addition, they had the following benefits of weekly monitoring of blood pressure, heart rate and respiratory rate.

\section{Results}

The sample was mostly composed of students. $57.6 \%$ of the participants were single, $54.5 \%$ did not have children. $72.7 \%$ do not perform another work activity. $78.8 \%$ practice a religion. $51.5 \%$ do not suffer from a disease. $60.6 \%$ perform physical activity, those who exercise are mainly students. $40 \%$ of the participants had an important life event in the last six months. The above can be seen in Table 1.

Regarding the SRI, it was observed that there was a significant 
decrease after the intervention (Table 2), the Student's T test was used for related samples, finding that the groups behaved differently. In relation to the variable cortisol in blood before and after the intervention, a decrease was observed, however, the difference was not statistically significant (Table 3 ). In the Table 4 the blood pressure, cardiac and respiratory rate before and after each nursing intervention are presented.

Table I Biosociodemographic characteristics

\begin{tabular}{|c|c|c|c|c|c|c|c|}
\hline Variables & & $\begin{array}{l}\text { Students } \\
\text { f(\%) }\end{array}$ & $\begin{array}{l}\text { Academics } \\
\mathrm{f}(\%)\end{array}$ & $\begin{array}{l}\text { Employees } \\
\mathrm{f}(\%)\end{array}$ & $\begin{array}{l}\text { Total } \\
\text { f(\%) }\end{array}$ & $\mathbf{X}^{2}$ & Value $p$ \\
\hline Type of participant & Status & $17(5 \mid .5)$ & $7(21.2)$ & $9(27.3)$ & $33(100)$ & 2.64 & \\
\hline \multirow{3}{*}{ Sex } & Female & $14(42.4)$ & $4(12.1)$ & $8(24.2)$ & $26(78.8)$ & 2.64 & 0.267 \\
\hline & Male & $3(9.1)$ & $3(9.1)$ & I (3.0) & $7(21.2)$ & & \\
\hline & Single & $16(48.5)$ & I (3.0) & $2(6.1)$ & $19(57.6)$ & & \\
\hline \multirow[t]{2}{*}{ Civil status } & Married & I (3.0) & $6(18.2)$ & $6(18.2)$ & $13(39.4)$ & 21.20 & .000 \\
\hline & Divorced & $0(0)$ & $0(0)$ & I (3.0) & I (3.0) & & \\
\hline \multirow{6}{*}{ Children } & Yes & I (3.0) & $6(18.2)$ & $8(24.2)$ & $15(45.5)$ & & \\
\hline & No & $16(48.5)$ & I (3.0) & I (3.09 & $18(54.5)$ & 22.10 & .000 \\
\hline & Middle school & & & I (3.0) & I (3.0) & & \\
\hline & High school & & & $3(9.1)$ & $3(9.1)$ & & \\
\hline & Technician degree & & & I (3.0) & I (3.0) & & \\
\hline & Coursing bachelor's degree & $13(39.4)$ & & I (3.0) & $14(42.4)$ & & \\
\hline \multirow[t]{6}{*}{ Scholarship } & Bachelor's Degree & & I (3.0) & $2(6.1)$ & $3(9.1)$ & 48.920 & .000 \\
\hline & Coursing master's degree & I (3.0) & & & 3.0 & & \\
\hline & Master's Degree & & $3(9.1)$ & I (3.0) & $4(12.1)$ & & \\
\hline & Coursing Doctorate degree & $3(9.1)$ & & & $3(9.1)$ & & \\
\hline & Doctor's degree & & $3(9.1)$ & & $3(9.1)$ & & \\
\hline & No & $12(36.4)$ & $6(18.2)$ & $6(18.2)$ & $24(72.7)$ & & \\
\hline \multirow[t]{4}{*}{ Additional occupation } & Second Job & $I(3.0)$ & I (3.0) & $2(6.1)$ & $4(12.1)$ & 3.944 & .479 \\
\hline & Attends school and has a job & $4(12.19$ & $0(0)$ & I (3.0) & $5(15.2)$ & & \\
\hline & None & $12(36.4)$ & $2(6.1)$ & $3(9.1)$ & $17(5 \mid .5)$ & & \\
\hline & Hypertension & $0(0)$ & $2(6.1)$ & I (0) & $2(6.1)$ & & \\
\hline \multirow[t]{6}{*}{ Suffers from illness } & Thyroid Disease & $2(6.1)$ & $2(6.1)$ & $389.1)$ & $7(21.2)$ & 16943 & 076 \\
\hline & Multiple sclerosis & $0(0)$ & $0(0)$ & I (3.0) & I (3.0) & & \\
\hline & Migraine & $0(0)$ & $0(0)$ & I (3.0) & I (3.0) & & \\
\hline & Others & $3(9.1)$ & I (3.0) & I (3.0) & $5(15.3)$ & & \\
\hline & None & II (33.3) & $3(9.1)$ & $4(12.1)$ & $20(60.6)$ & & \\
\hline & Family member deceased & I (3.0) & $0(0)$ & I (3.0) & $2(6.1)$ & & \\
\hline \multirow{3}{*}{$\begin{array}{l}\text { Important life event } \\
\text { in the past six } \\
\text { months }\end{array}$} & Disease diagnostic & I (3.0) & $0(0)$ & $2(6.1)$ & $3(9.1)$ & 5.136 & .743 \\
\hline & Economic Issues & I (3.0) & $0(0)$ & $0(0)$ & I (3.0) & & \\
\hline & Family conflict & $3(9.1)$ & $2(6.1)$ & $2(6.1)$ & $7(2 \mid .2)$ & & \\
\hline
\end{tabular}

Source: self-elaborated with data from biosociodemographic and health collection card. $n=33$ 
Table 2 Stress reactivity index before and after the intervention

\begin{tabular}{lllllll}
\hline \multirow{2}{*}{ Variable } & \multirow{2}{*}{ Mean } & SD & \multicolumn{2}{c}{ Confidence intervals } & \multirow{2}{*}{$\boldsymbol{T}$} & \multirow{2}{*}{$\boldsymbol{P}$} \\
\cline { 5 - 6 } & & & Inferior & Superior & & \\
\hline SRI pre- intervention & 1.68 & .68 & .57 & 1.02 & 7.20 & .000 \\
SRI post-intervention & .88 & .44 & & & & \\
\hline
\end{tabular}

Source: self-elaborated with data from SRI Gonzales de Rivera. $n=33$

Table 3 Cortisol in blood before and after the intervention

\begin{tabular}{lcclccc}
\hline Variable & Mean & SD & \multicolumn{2}{c}{ Confidence intervals } & T & P \\
\cline { 4 - 5 } & Inferior & Superior & & \\
\hline $\begin{array}{l}\text { Cortisol in blood pre- } \\
\text { intervention }\end{array}$ & 12.78 & 5.29 & -1.22 & 3.08 & .876 & .387 \\
$\begin{array}{l}\text { Cortisol in blood post- } \\
\text { intervention }\end{array}$ & 11.85 & 4.75 & & & \\
\hline
\end{tabular}

Source: self-elaborated with data from the participants clinical analysis, University of Sonora. $n=33$

Table 4 Blood pressure, cardiac and respiratory rate before and after each intervention session

\begin{tabular}{|c|c|c|c|c|c|c|c|}
\hline \multicolumn{8}{|c|}{$\begin{array}{l}\text { Breathing techniques and progressive muscle relaxation accompanied by aromatherapy } \\
\text { and music therapy }\end{array}$} \\
\hline & & \multirow[t]{2}{*}{ Mean } & \multirow[t]{2}{*}{ SD } & \multicolumn{2}{|c|}{$\begin{array}{l}95 \% \text { confidence } \\
\text { interval }\end{array}$} & \multirow[t]{2}{*}{$T$} & \multirow[t]{2}{*}{$p$} \\
\hline & & & & Inferior & Superior & & \\
\hline & Pre & 112.24 & 18.6 & .65 & 13.83 & 2.23 & .032 \\
\hline \multicolumn{8}{|l|}{ Systolic BP } \\
\hline & Post & 108.48 & & & & & \\
\hline \multirow{2}{*}{ Diastolic BP } & Pre & 66.96 & 8.26 & -1.87 & 3.99 & .73 & .467 \\
\hline & Post & 68.03 & & & & & \\
\hline \multirow{2}{*}{ Cardiac rate } & Pre & 78.69 & 8.68 & 1.54 & 8.11 & 3.21 & .003 \\
\hline & Post & 74.42 & & & & & \\
\hline \multirow{2}{*}{ Respiratory rate } & Pre & 18.87 & 1.40 & I.4I & 2.40 & 7.8 & .000 \\
\hline & Post & 16.84 & & & & & \\
\hline \multicolumn{8}{|c|}{ Guided meditation accompanied by aromatherapy and music therapy } \\
\hline & & \multirow{2}{*}{ Mean } & \multirow{2}{*}{ SD } & \multicolumn{2}{|c|}{$\begin{array}{l}95 \% \text { confidence } \\
\text { interval }\end{array}$} & $T$ & $p$ \\
\hline & & & & Inferior & Superior & & \\
\hline \multirow{2}{*}{ Systolic BP } & Pre & 113.64 & 8.72 & .84 & 7.03 & 2.59 & .014 \\
\hline & Post & 109.24 & & & & & \\
\hline \multirow[t]{4}{*}{ Diastolic BP } & Pre & 69.54 & 8.63 & -4.12 & 2.00 & -.70 & .486 \\
\hline & Post & 68.48 & & & & & \\
\hline & Pre & & & & & & \\
\hline & & 78.42 & 9.62 & 1.13 & 7.95 & 2.71 & .011 \\
\hline \multicolumn{8}{|l|}{ Cardiac rate } \\
\hline \multirow{3}{*}{ Respiratory rate } & Post & 73.15 & & & & & \\
\hline & Pre & 18.27 & 1.13 & 1.62 & 2.43 & 10.30 & .000 \\
\hline & Post & 16.63 & & & & & \\
\hline
\end{tabular}

Relaxation and stretching exercises accompanied with aromatherapy and music therapy 


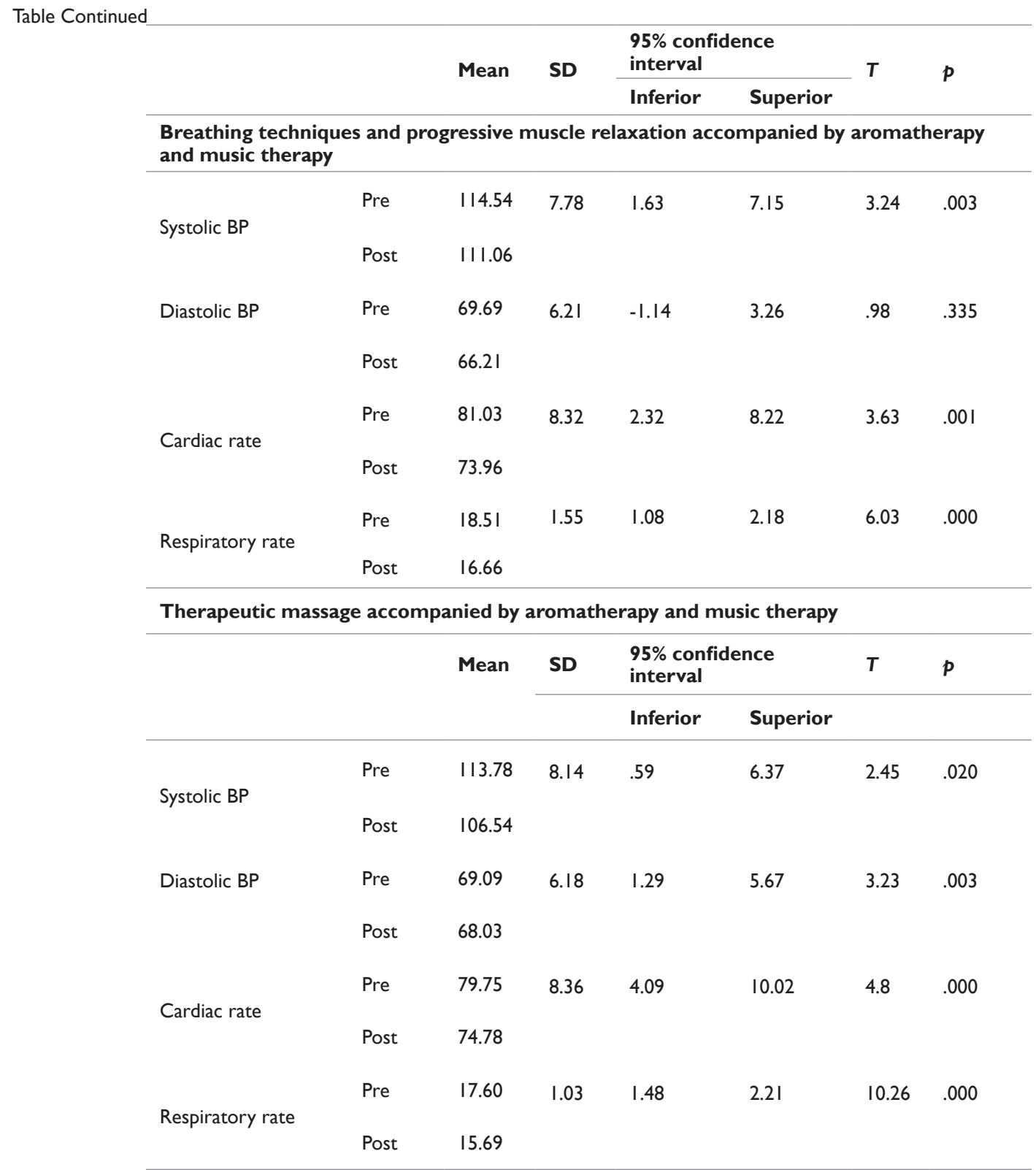

Source: self-elaborated with data from physiological measures, University of Sonora. $n=33$

\section{Discussion}

The general objective of this research was to determine the effect of nursing interventions for stress management on employees, academics, and university students. In the analysis of biosociodemographic characteristics, it was found that the female sex was predominantly, women. These had a better attachment to the interventions when compared with men. This aspect coincides with that reported in the literature regarding gender, since it was found that women and men react differently when it comes to managing different situations of threat or stressors. In man, a predominant set-up of the prefrontal cortex has been established: this would favor the behavior of "fight or flight". In women, the reaction to stress would be built on the processes of attraction; in which the limbic system activates a behavior "of help and protection" and makes it seek help and stick to it for the struggle to survive. What could be interpreted that men and women have different responses to stress. ${ }^{14}$

Scientists interested in knowing the causes of emotional distress, found that there are stress situations that generally affect people psychologically, such as divorce, academic examinations, loss of loved ones, care of family with physical disability, diagnosis of chronic diseases and economic difficulties. ${ }^{15}$ All the above aspects also coincide with what was found in the present study, regarding the presence of important events in recent months, most of the participants lived through a family conflict, to mention a few, the participants said that they have passed through the death of a relative, several students report having economic problems, adding an additional stressor besides the academic load.

To describe the effect of each intervention session on physical 
health indicators such as blood pressure, pulse and respiration, were obtained before and after each session. The result show that there were changes in the physical indicators of health, systolic and diastolic blood pressure, heart rate and respiratory rate, since there was a decrease in their levels. This data coincides with a study that mentions that yoga decreases the diastolic blood pressure, cholesterol levels (HDL) and triglycerides of the participants. ${ }^{9}$ In all of the nursing sessions, vital signs decreased, with the exception of diastolic blood pressure, which increased slightly in guided meditation, however this did not show statistically significant differences. The scientific evidence found about the negative impact of chronic stress on the brain, the nervous system, endocrine and immune clarifies that this negative impact represents an important factor in the etiology and progress of a large number of diseases and performing these types of interventions for a prolonged period of time could benefit every individual to acquire forms of coping stressful situations that life will present and at the same time reduce the risk of suffering illnesses related to stress. ${ }^{14}$

The decrease in vital signs before the nursing interventions and counseling can be explained due to the fact that the participants underwent relaxation therapies. There is evidence that the inspirations become deeper, slower and more rhythmic after performing meditation. ${ }^{15}$ It is important to mention that the first blood sample was taken halfway through the semester shortly before the university community began its vacation period, where it can be assumed that the university community was not in a demanding or stressful period in relation to their activities. While the second blood sample was obtained at the end of the semester period. The results of the cortisol levels can be attributed to the above, which were low but did not present statistically significant differences, considering this as an external conditioning factor, even when the sample of the population underwent the nursing interventions and counseling for stress management. The purpose of comparing blood cortisol levels before and after exposing the sample of the university community to the nursing interventions was to probe the effect of interventions on cortisol levels. The general average, as the average broken down in students, academics and employees, of the blood cortisol level after the nursing intervention, are within the normal values of cortisol in the morning.

The desired outcome was the find minor levels in the second analysis. The results showed that the cortisol measure indeed decreased from $12.78 \mu \mathrm{g} / \mathrm{dL}$ to $11.85 \mu \mathrm{g} / \mathrm{dL}$. It must be added that cortisol increases in response to psychological stress and there are numerous situations beyond the scope or control of the nursing interventions. Furthermore stress and itself in the physiological life of human beings, environmental, cultural, social, attitudinal factors and personality traits also fulfill the role of modulating the physiological response of stress. ${ }^{15}$

\section{Conclusion}

Nursing interventions for stress management showed a significant effect in the decrease of the SRI, decrease in the mean cortisol after the interventions provided, and changes in the vital signs before and after each session. It should be noted that there are important external factors such as: end of semester where stress and academic load increases, in relation to final exams, in addition to important life events, such as problems regarding financial situation, family conflicts, among others. All these situations influence the results, therefore, it is necessary to continue with this type of research. However, given the complexity of the human being, it is difficult to isolate the previously listed factors. The total SRI of all the participants showed a decrease, which reflects subjective data about the physical and psychological manifestations of stress and that knowledge about their stress management was acquired, attaining a reduction of stress in the participants during the time of the interventions. It is important to emphasize that the effect of the nursing interventions was positive, the SRI of the studied population decreased considerably, in addition the evaluation of subjectivity and receptivity of the participants was favorable. It is considered suitable to start with this type of intervention with individuals such as children and adolescents, to promote health, prevent diseases and thereby reduce the risks of illnesses related to chronic stress. The results of this investigation allows to affirm that the decrease of the stress reactivity index, the hormone cortisol and the physical manifestations of stress, creates a feeling of internal well-being and self-control of one's own emotions, which provides capacity to increase well-being and optimism in participants.

\section{Acknowledgements}

None.

\section{Conflict of interest}

The author declares no conflict of interest.

\section{References}

1. http://cuentame.inegi.org.mx/poblacion/defunciones.aspx?tema $=\mathrm{P}$

2. https: //medlineplus.gov/english/article/003211.htm

3. Anderson NB. Levels of analysis in health science: a framework for integrating sociobehavioral and biomedical research. Ann N Y Acad Sci. 1998;840:563-576.

4. Medina N, Canaval G. Stress and emotions in coronary diseases. Achichan 2010;10:19-33.

5. Williams RB. Blood pressure reactivity to psychological stress: a new risk factor for coronary disease. Hypertension. 2006;47(3): 329-330.

6. Williams S, Cooper L. Management of stress at work, detailed plan for professionals. 1st ed. Mexico: Modern Manual; 2004.

7. http://pendientedemigracion.ucm.es/info/seas/estres_lab/el_estres.htm

8. Hazlett-Stevens H, Oren Y. Effectiveness of mindfulness-based stress reduction bibliotherapy: a preliminary randomized controlled trial. $J$ Clin Psychol. 2017;73(6):626-637.

9. Hartley L, Dyakova M, Holmes J, et al. Yoga for the primary prevention of cardiovascular disease. Cochrane Database Sys Rev. 2014;(5):CD010072.

10. Pinto M, Ruiz P. Integration of alternative medicine in health services in Colombia. Aquichan. 2012;12(2):183-193

11. Watson J. Nursing: The philosophy and science of caring. Colorado USA: University Press of Colorado Boulder; 2008.

12. Bulechek G, Butcher H, Dochterman J, et al. Classification of Nursing Interventions (NIC). Sixth edition. Spain: Elsevier; 2013.

13. Hernández R, Collado C, Lucio $P$, et al. Fundamentals of research methodology. Madrid; McGraw-Hill; 2010.

14. Duval Fabrice, González Félix, Rabia Hassen. Neurobiology of stress. Rev chil neuro-psychiatr. 2010;48(4):307-318.

15. Moscoso S Manolete. From the mind to the cell: impact of stress on psychoneuroimmunoendocrinology. Bast. 2009;15(2):143-152. 